\title{
Trends in prevalence of gestational diabetes mellitus in Zhejiang Province, China, 2016-2018
}

\author{
Meng Wang, Ru-Ying Hu, Wei-Wei Gong, Jin Pan, Fang-Rong Fei, Hao Wang, Xiao-Yan Zhou, Jie-Ming Zhong* \\ and Min Yu*
}

\begin{abstract}
Background: Limited population-based studies have investigated the secular trend of prevalence of gestational diabetes mellitus (GDM) in mainland China. Therefore, this study aimed to estimate the prevalence of GDM and time trends in Chinese female population.

Methods: Based on Diabetes Surveillance System of Zhejiang Province, 97,063 diagnosed GDM cases aged 20-50 years were identified from January 1, 2016 to December 31, 2018. Annual prevalence, prevalence rate ratios (PRRs) and average annual percentage change with their 95\% confidence intervals (Cls) were reported.
\end{abstract}

Results: The age-standardized overall prevalence of GDM was reported to be 7.30\% (95\% Cl 7.27-7.33\%); 9.13\% (95\% $\mathrm{Cl} 9.07-9.19 \%)$ in urban areas and 6.24\% (95\% Cl 6.21-6.27\%) in rural areas. Compared with 20-24 years age group, women in advanced age groups (25-50 years) were at higher risk for GDM (PRRs ranged from 1.37 to 8.95 and the 95\% Cls did not include the null). Compared with rural areas, the risk for GDM was higher in urban areas (PRR: 1.69, $95 \% \mathrm{Cl} 1.67-1.72$ ). The standardized annual prevalence increased from $6.02 \%$ in 2016 to $7.94 \%$ in 2018 , with an average annual increase of $5.48 \%$, and grew more rapidly in rural than urban areas (11.28\% vs. $0.00 \%)$.

Conclusions: This study suggested a significant increase in the prevalence of GDM among Chinese female population in Zhejiang province during 2016-2018, especially in women characterized by advanced age and rural areas.

Keywords: Gestational diabetes mellitus, Prevalence, Epidemiology

\section{Background}

Gestational diabetes mellitus (GDM) is characterized by high blood glucose levels during any time of pregnancy (although most likely after week 24). Based on up-to-date estimates from the International Diabetes Federation (IDF), 20.4 million or $15.8 \%$ of live births to women in 2019 had some form of hyperglycaemia in pregnancy, of which, $83.6 \%$ were due to GDM [1]. As one of the most common medical complications in pregnancy, GDM can not only affect the short-term maternal and fetal outcomes [2, 3], but significantly increase the risks of long-term adverse health consequences both

*Correspondence: jmzhongcdc@163.com; mycdc1234@163.com Zhejiang Provincial Center for Disease Control and Prevention, 3399 Binsheng Road, Hangzhou 310051, China for mothers and their offspring, such as metabolic syndrome, cardiovascular disease and obesity [4-8]. Due to different screening strategies, diagnostic criteria and population characteristics, the prevalence of GDM is varied across populations worldwide, ranging from $<1$ to $28 \%$ [9]. In recent decades, a dramatically rising trend of GDM among pregnant women has been observed in the international studies and the subsequent health and economic burden have drawn much public health attentions $[10,11]$. Asia has the largest population and Asian ethnicity has been reported to be one of the most important risk factors for GDM [12, 13], while relevant estimates of secular trends are still scant, especially in the developing countries. With the national health insurance database covering $97 \%$ of the population, a study in Korea reported that the prevalence of GDM among women

c) The Author(s) 2021. This article is licensed under a Creative Commons Attribution 4.0 International License, which permits use, sharing, adaptation, distribution and reproduction in any medium or format, as long as you give appropriate credit to the original author(s) and the source, provide a link to the Creative Commons licence, and indicate if changes were made. The images or other third party material in this article are included in the article's Creative Commons licence, unless indicated otherwise in a credit line to the material. If material is not included in the article's Creative Commons licence and your intended use is not permitted by statutory regulation or exceeds the permitted use, you will need to obtain permission directly from the copyright holder. To view a copy of this licence, visit http://creativecommons.org/licenses/by/4.0/. The Creative Commons Public Domain Dedication waiver (http://creativecommons.org/publicdomain/zero/1.0/) applies to the data made available in this article, unless otherwise stated in a credit line to the data. 
reached 5.7-9.5\% during the period 2009-2011[14]. For Chinese population, two independent studies performed across mainland China in 2006 and 2015 showed that the prevalence of GDM was $4.3 \%$ and $3.7 \%[15,16]$. However, due to the heterogeneous in study design, participants and diagnostic criteria, it is difficult to understand the time trend of GDM at the national level. In recent decades, a very few regional studies have attempted to examine the secular trends of GDM among Chinese population. Among them, successive surveys in Tianjin city suggested that the prevalence of GDM increased by 3.5 times (from 2.3 to $8.1 \%$ ) during 1999-2012 in women living in urban districts [17-19]. Another study of 13,738 GDM cases, conducted in Xiamen, which is an economically developed city, reported a high but relatively stable prevalence of GDM (ranging from 15.5 to $19.9 \%$ ) among pregnant women during 2012-2017 [20]. Nevertheless, considering the limited sample size, as well as study period and regional representation in these studies, the up-to-date estimates of secular trends in GDM among Chinese women were warranted. The present study aimed to evaluate the GDM prevalence and time trends in Chinese female population during $2016-2018$ by age, residence area and calendar year.

\section{Methods}

\section{Data sources}

Data used in this study came from the Diabetes Surveillance System of Zhejiang province, which was a population-based diabetes registry system established in 2001 by Zhejiang Provincial Center for Disease control and Prevention (CDC). At the beginning of establishment, the system covered 30 representative surveillance districts and over 16 million residents. As early as 2009, the surveillance system has extended to all 90 districts throughout the province, with approximately 48 million residents. The surveillance procedures and quality control measures have been described elsewhere [21, 22] and are thus only briefly recounted here. All types of diabetes cases (i.e., type 1 , type 2 , gestational or other diabetes) were diagnosed and reported by certificated health practitioners in local hospitals and health services centers. Once the diabetes cases were diagnosed, the patients' information regarding demographics, diagnosis and laboratory indicators were registered in the system within a week. To make sure that only the newly-diagnosed cases were recorded, the patients registered in the system were further verified according to the characteristics of identity card number as well as full name, gender, date of birth (year and month) and region code. For GDM, it is worth noting that if the event recurred in the same patient during another pregnancy, then the case was considered as an independent new record. Later, the confirmed and recorded patients would be followed-up once per year by the health practitioners in local health services centers. All the recorded diabetes cases were coded according to the International Classification of Disease 10th revision (ICD-10).

\section{GDM cases diagnosis}

In this study, GDM cases were diagnosed with the onestep method according to "The Diagnostic Criteria for GDM (2014)" published by the Chinese Medical Association [23]. Specifically, between 24 and 28 weeks of gestation, a diagnostic 2-h 75-g oral glucose tolerance test was carried out among pregnant women. Women were classified as having GDM when one of the following plasma glucose values was reached or exceeded: $0 \mathrm{~h}, 5.1 \mathrm{mmol} / \mathrm{L}$; $1 \mathrm{~h}, 10.0 \mathrm{mmol} / \mathrm{L}$; or $2 \mathrm{~h}, 8.5 \mathrm{mmol} / \mathrm{L}$.

\section{Number of births}

Due to the lack of direct data on births in this study, we used the number of children to evaluate the number of births given the small probability of a multiple birth. The number of children in each year was evaluated according to the number of childbearing female population (20-50 years) in a year multiplied by the fertility rate of population, which is the average number of children that would be born to a woman over her lifetime. The data on female population of childbearing age in each year were obtained from the Zhejiang Provincial Statistics Bureau and were calculated with the female resident number estimated at the beginning and end of each year (i.e., midyear population). The age-specific fertility rates data in Zhejiang province were from the sixth population census in China, 2010.

\section{Statistical analysis}

Descriptive statistics were used to describe the baseline characteristics of 2016-2018 GDM cases included in the present study with frequency and proportion. The crude prevalence was calculated as the number of GDM cases divided by the number of births. The prevalence was calculated for each age group (20-24, 25-29, 30-34, $35-39,40-44,45-50$ years) and calendar year (20162018), stratified by residence area (urban and rural). The standardized prevalence was calculated using the direct standardization method according to the sixth population census in Zhejiang, 2010. To explore the effects of diagnosis year, age and residence area on prevalence, Poisson regression models were conducted with reporting the prevalence rate ratio (PRR) and 95\% confidence intervals (CIs). Within the model, the calendar year was treated as a dummy variable. To examine the time trends of T2DM, the average annual percentage change in prevalence was calculated in multivariable Poisson regression 
model. Meanwhile, within the model, the calendar year was treated as a continuous variable and the statistical significance of the regression coefficient was tested. All analyses were performed using SAS statistical package (version 9.2, SAS Institute, Inc., Cary, NC, USA).

\section{Results}

Overall, 97,063 GDM cases aged 20-50 years diagnosed between January 1, 2016 and December 31, 2018 were included in this analysis. The mean age at diagnosis was 31.37 (4.86) years. The detailed baseline characteristics of GDM cases included in the study were shown in Table 1.

\section{Residence area}

During 2016 and 2018, the crude overall prevalence of GDM was 10.01\% (95\% CI 9.95-10.07\%). Standardized overall prevalence of GDM during the same period was estimated at $7.30 \%$ (95\% CI 7.27-7.33\%); 9.13\% (95\% CI 9.07-9.19\%) in urban areas and 6.24\% (95\% CI $6.21-6.27 \%$ ) in rural areas (Table 2). After adjusting for the covariates in the Poisson regression models, the risk for GDM was 1.69 times (PRR: 1.69, 95\% CI 1.67-1.72) higher in urban areas (Table 3 ).

\section{Age groups}

The mean prevalence was significantly different across all age groups, among which, ranged from 2.55 (95\% CI $2.48-2.61 \%)$ to $24.56 \%$ (95\% CI $23.99-25.13 \%)$ in total; $3.59 \%$ (95\% CI $2.99-4.26 \%$ ) to $32.99 \%$ (95\% CI $32.46-33.51 \%$ ) in urban areas, and $1.94 \%$ (95\% CI $1.88-$ $2.01 \%$ ) to $21.47 \%$ (95\% CI $20.78-22.17 \%$ ) in rural areas. The highest GDM prevalence was seen in 40-44 years age group, followed by $35-39,30-34,25-29,45-50$,

Table 1 Baseline characteristics of gestational diabetes mellitus cases included in this study, 2016-2018

\begin{tabular}{ll}
\hline & $\begin{array}{l}\text { Gestational } \\
\text { diabetes } \\
\text { mellitus }\end{array}$ \\
\hline $\begin{array}{l}\text { Number of cases } \\
\text { Mean age at diagnosis (SD), year }\end{array}$ & 97,063 \\
Age groups at diagnosis, years (\%) & $31.37(4.86)$ \\
20-24 & \\
25-29 & $6,137(6.32)$ \\
30-34 & $32,525(33.51)$ \\
35-39 & $32,057(33.03)$ \\
$40-44$ & $20,627(21.25)$ \\
$45-50$ & $5,410(5.57)$ \\
Residence area & $307(0.32)$ \\
Urban (\%) & \\
Rural (\%) & $48,525(49.99)$ \\
\hline
\end{tabular}

and 20-24 years age groups (Table 2). Compared with 20-24 years age group, 25-29, 30-34, 35-39, 40-44 and 45-50 years age groups were at significantly higher risk for GDM, with the PRR were 3.00 (95\% CI 2.92-3.08), 5.64 (95\% CI 5.49-5.80), 8.95 (95\% CI 8.69-9.20), 8.14 (95\% CI 7.85-8.44) and 1.37 (95\% CI 1.22-1.54), respectively (Table 3 ).

\section{Prevalence time trends}

Annual prevalence and average annual percentage changes of prevalence were shown in Tables 4 and 5 . Overall, the prevalence of GDM increased in all age groups. Specifically, in total, the standardized annual prevalence increased from $6.02 \%$ in 2016 to $7.94 \%$ in 2018 , with an average annual increase of $5.48 \%$ (95\% CI 4.67-6.30\%). In urban areas, the prevalence increased from 2.82 to $5.07 \%$, while in rural areas, the prevalence increased from 3.29 to $5.46 \%$. The average annual percentage change was greater in rural areas $(11.28 \%, 95 \%$ CI $10.07-12.51 \%)$ than in urban areas $(0.00 \%, 95 \% \mathrm{CI}$ -1.08 to $1.10 \%)$.

\section{Discussion}

In the present study, with data from the populationbased diabetes registry system in Zhejiang province of China, we have reported the prevalence and time trends of GDM in women of childbearing age during 2016-2018 and examined the effects of age and residence area on these estimates. Overall, our results suggested that there was a significant increase in the prevalence of GDM, which was also observed by age and residence area. To our knowledge, this is one of the few studies to investigate the prevalence and time trend of GDM in Chinese female population.

During 2016-2018, we showed that the age-standardized overall prevalence of GDM was $7.30 \%(9.13 \%$ in urban areas and 6.24\% in rural areas) among Chinese women aged 20-50 years. Although with different GDM diagnostic criteria, study designs, population characteristics, study periods and statistical methods, our results were comparable to those findings from the published studies at present. Using the 1999 WHO criteria, two population-based studies in Tianjin of China reported that the adjusted prevalence of GDM among women living in urban districts between time-points 1999-2008 and $2010-2012$ was $4.9 \%$ and $8.1 \%$, respectively $[18,19]$. In a claims-based analysis conducted in the neighboring country of Korea, the age-adjusted prevalence of GDM in 2009-2011 was 7.5\% [14], which was similar to our estimate. In Denmark, a national register-based cohort study of all pregnancies resulting in a birth reported the combined prevalence of GDM was 2.7\% (2.4\% among Danish born women and $4.3 \%$ among immigrant women) 
Table 2 Mean prevalence of gestational diabetes mellitus, 2016-2018

\begin{tabular}{|c|c|c|c|c|}
\hline Age at diagnosis (years) & Number of cases & Number of births & Prevalence (\%) & $95 \% \mathrm{Cl}(\%)$ \\
\hline \multicolumn{5}{|l|}{ Overall } \\
\hline $20-24$ & 6137 & 241,055 & 2.55 & $2.48-2.61$ \\
\hline $25-29$ & 32,525 & 397,700 & 8.18 & $8.09-8.26$ \\
\hline $30-34$ & 32,057 & 216,381 & 14.82 & $14.67-14.97$ \\
\hline $35-39$ & 20,627 & 85,276 & 24.19 & $23.90-24.48$ \\
\hline $40-44$ & 5410 & 22,028 & 24.56 & $23.99-25.13$ \\
\hline $45-50$ & 307 & 6813 & 4.51 & $4.03-5.02$ \\
\hline $20-50$ & 97,063 & 969,252 & 10.01 & $9.95-10.07$ \\
\hline Standardized prevalence ${ }^{a}$ & 212,266 & $2,907,756$ & 7.30 & $7.27-7.33$ \\
\hline \multicolumn{5}{|l|}{ Urban areas } \\
\hline $20-24$ & 2644 & 57,385 & 4.61 & $4.44-4.78$ \\
\hline $25-29$ & 16,364 & 138,443 & 11.82 & $11.65-11.99$ \\
\hline $30-34$ & 16,671 & 81,240 & 20.52 & $20.24-20.80$ \\
\hline $35-39$ & 10,253 & 31,082 & 32.99 & $32.46-33.51$ \\
\hline $40-44$ & 2470 & 9614 & 25.69 & $24.82-26.58$ \\
\hline $45-50$ & 123 & 3429 & 3.59 & $2.99-4.26$ \\
\hline $20-50$ & 48,525 & 321,193 & 15.11 & $14.98-15.23$ \\
\hline Standardized prevalence ${ }^{a}$ & 87,975 & 963,579 & 9.13 & $9.07-9.19$ \\
\hline \multicolumn{5}{|l|}{ Rural areas } \\
\hline $20-24$ & 3493 & 179,652 & 1.94 & $1.88-2.01$ \\
\hline $25-29$ & 16,161 & 255,185 & 6.33 & $6.24-6.43$ \\
\hline $30-34$ & 15,386 & 118,536 & 12.98 & $12.79-13.17$ \\
\hline $35-39$ & 10,374 & 51,245 & 20.24 & $19.90-20.59$ \\
\hline $40-44$ & 2940 & 13,695 & 21.47 & $20.78-22.17$ \\
\hline $45-50$ & 184 & 4292 & 4.29 & $3.70-4.94$ \\
\hline $20-50$ & 48,538 & 622,605 & 7.80 & $7.73-7.86$ \\
\hline Standardized prevalence ${ }^{a}$ & 116,552 & $1,867,818$ & 6.24 & $6.21-6.27$ \\
\hline
\end{tabular}

$\mathrm{Cl}$ confidence interval

a Age-standardized to the 6th population census in Zhejiang Province, 2010

between 2004 and 2015 [24]. In contrast, regional data from Aarhus city of Denmark demonstrated that the GDM prevalence was $4.3 \%$ during the period of 20132016 [25]. Besides, within a population-based cohort study in northeastern Pomerania of Germany, the authors found the rate was 5.1\% between 2002 and 2008 [26]. In the last decades, studies on GDM prevalence were also attempted in the United States. For example, using a medical insurance claims-based database within the time frame of 2004-2011, the GDM prevalence was found to be $6.29 \%$ among 839,792 pregnancies [27]. More recently, in the National Health and Nutrition Examination Surveys 2007-2014, the prevalence of GDM among U.S. women aged $\geq 20$ years was found to be $7.6 \%$ [28].

In our study, the age-standardized annual prevalence of GDM increased from $6.02 \%$ in 2016 to $7.94 \%$ in 2018, with the average annual percentage change of $5.48 \%$, which was similar to other results in previous literature. Of 156,144 women who gave birth in southern Sweden, a study showed that the prevalence of GDM was $1.9 \%$ in 2003 and $2.6 \%$ in 2012, which rose at an annual rate of $3.4 \%$ [29]. Another study conducted in Sydney of Australia also indicated that the average prevalence of women with GDM increased from $8.7 \%$ in 2011 to $13.9 \%$ in 2017, an increase of $9 \%$ annually [30]. Although reasons for the rising trend of GDM in our study were unclear, there were several possible explanations with respect to the increasing prevalence of the undiagnosed diabetes, GDM related factors, and a declining missing report rate of the diabetes surveillance system. Nationally representative surveys have indicated that the prevalence of undiagnosed diabetes in Chinese women rose from $5.2 \%$ in 2007 to $6.1 \%$ in 2013 [31, 32]. When these diabetes patients were firstly detected during pregnancy, they were usually diagnosed as GDM cases. According to convincing evidence, the higher pre-pregnancy body mass index (BMI) was one of the strongest risk factors of GDM and the increasing prevalence of GDM might 
Table 3 Prevalence rate ratios (PRR) of gestational diabetes mellitus in relation to calendar year and demographic factors

\begin{tabular}{|c|c|c|c|c|c|c|}
\hline \multirow[t]{2}{*}{ Characteristic } & \multicolumn{2}{|c|}{ Urban } & \multicolumn{2}{|l|}{ Rural } & \multicolumn{2}{|l|}{ All } \\
\hline & PRR & $95 \% \mathrm{Cl}$ & PRR & $95 \% \mathrm{Cl}$ & PRR & $95 \% \mathrm{Cl}$ \\
\hline \multicolumn{7}{|l|}{ Year } \\
\hline 2016 & Ref & & Ref & & Ref & \\
\hline 2017 & 0.99 & $0.97-1.02$ & 1.21 & $1.18-1.23$ & 1.09 & $1.08-1.11$ \\
\hline 2018 & 0.97 & $0.95-0.99$ & 1.22 & $1.20-1.25$ & 1.09 & $1.07-1.10$ \\
\hline \multicolumn{7}{|l|}{ Age } \\
\hline 20-24 years & Ref & & Ref & & Ref & \\
\hline $25-29$ years & 2.57 & $2.46-2.67$ & 3.26 & $3.14-3.38$ & 3.00 & $2.92-3.08$ \\
\hline 30-34 years & 4.46 & $4.28-4.64$ & 6.66 & $6.42-6.91$ & 5.64 & $5.49-5.80$ \\
\hline 35-39 years & 7.16 & $6.86-7.48$ & 10.39 & $10.00-10.80$ & 8.95 & $8.69-9.20$ \\
\hline 40-44 years & 5.58 & $5.28-5.89$ & 11.04 & $10.51-11.60$ & 8.14 & $7.85-8.44$ \\
\hline $45-50$ years & 0.78 & $0.65-0.93$ & 2.20 & $1.90-2.55$ & 1.37 & $1.22-1.54$ \\
\hline \multicolumn{7}{|l|}{ Residence area } \\
\hline Urban & & & & & 1.69 & $1.67-1.72$ \\
\hline Rural & & & & & Ref & \\
\hline
\end{tabular}

PRR prevalence rate ratios, $\mathrm{Cl}$ confidence interval, Ref. reference

Multivariable Poisson regression model with the calendar year as a dummy variable

reflect the current patterns of increasing obesity [33, 34]. Four national surveys showed that the prevalence of obesity among Chinese women aged $20-59$ years increased from $7.5 \%$ in 2000 , to $8.4 \%$ in $2005,9.2 \%$ in 2010 , and $9.3 \%$ in 2014, with the annual percentage change of $0.13 \%$ [35]. Physical activity was found to be associated with odds of GDM [36, 37], while Chinese national surveys showed that the percentage of women meeting the minimum leisure-time physical activity increased over time $(15.9 \%$ in $2002,16.9 \%$ in 2005 , and $22.1 \%$ in 2014 ) [35]. GDM was also reported to be associated with higher parity [12]. However, according to the China Kadoorie Biobank (CKB) study conducted during 2004-2008, the mean parity fell (urban: 4.9-1.1; rural 5.9-1.4) among 300,000 Chinese women aged 30-79 years [38]. Besides, advanced maternal age is an independent risk factor for GDM $[39,40]$ and based on our analysis, the mean age at GDM diagnosis increased from 30.89 to 31.61 years during 2016-2018. Notably, in 2015, the Chinese government announced that all couples would be allowed to have two children. Based on a national cross-sectional study in 2016-2017, four in ten women of childbearing age planned to have a second child, especially for women of an advanced age [41]. Except for the contributions of the diabetes related factors, the rising trend of GDM might also be attributed to the efficiency change of the diabetes surveillance system. In 2009, we begun to use the completely computerized diabetes surveillance system, with more convenient case-reporting procedure and stricter quality control measures, the rate of missing report was diminishing.
Age disparities in GDM prevalence have been observed in previous reports $[14,42]$. In accordance with these studies, our results showed higher prevalence of GDM in women with advanced age. Besides, we found that the prevalence of GDM was slightly higher in urban area than that in rural area, consistent with the findings in an India study [43], but different from another national study in Turkey showing that there was no difference in GDM prevalence between urban and rural regions [44]. Furthermore, importantly, our analysis showed a greater average annual increase in prevalence in rural area than in urban area, which suggested a more rapid growth of GDM in rural area and necessary intervention measures must be implemented.

Our study had several strengths. This is one of the few studies to investigate the prevalence and time trend of GDM among Chinese female population in mainland China. Data analyzed in the study were extracted from the computerized diabetes surveillance system, which was continually able to monitor the odds of GDM among province-wide population. With a relatively larger sample of 97,063 cases diagnosed by certificated health practitioners, the prevalence and time trends of GDM during 2016-2018 were reported eventually. Meanwhile, some limitations must be considered in this study. The greatest weakness of the study is that our reported data on GDM prevalence might be under-estimated. First, due to the lack of direct data on births, we used the number of children to evaluate the number of births, with neglecting the small probability of a multiple birth. Second, we have conducted several 
Table 4 Annual prevalence of gestational diabetes mellitus, 2016-2018

\begin{tabular}{|c|c|c|c|}
\hline Characteristic & 2016 & 2017 & 2018 \\
\hline \multicolumn{4}{|l|}{ Overall } \\
\hline $\begin{array}{l}\text { Mean age at diagnosis (SD), } \\
\text { year }\end{array}$ & $30.89(4.74)$ & $31.59(4.94)$ & $31.61(4.85)$ \\
\hline Number of cases & 30,821 & 33,399 & 32,843 \\
\hline Number of births & 330,089 & 323,845 & 315,318 \\
\hline Prevalence (\%) & 9.34 & 10.31 & 10.42 \\
\hline Standardized prevalence ${ }^{\mathrm{a}}(\%)$ & 6.02 & 7.98 & 7.94 \\
\hline \multicolumn{4}{|l|}{ Urban areas } \\
\hline Number of cases & 16,427 & 16,267 & 15,831 \\
\hline Number of births & 109,054 & 107,029 & 105,110 \\
\hline Prevalence (\%) & 15.06 & 15.20 & 15.06 \\
\hline Standardized prevalence ${ }^{\mathrm{a}}(\%)$ & 8.24 & 9.66 & 9.50 \\
\hline \multicolumn{4}{|l|}{ Rural areas } \\
\hline Number of cases & 14,394 & 17,132 & 17,012 \\
\hline Number of births & 212,430 & 208,406 & 201,770 \\
\hline Prevalence (\%) & 6.78 & 8.22 & 8.43 \\
\hline Standardized prevalence ${ }^{\mathrm{a}}(\%)$ & 4.81 & 7.01 & 6.94 \\
\hline \multicolumn{4}{|l|}{ Urban areas (\%) } \\
\hline 20-24 years & 5.16 & 4.71 & 3.90 \\
\hline $25-29$ years & 12.70 & 11.43 & 11.26 \\
\hline 30-34 years & 21.09 & 19.91 & 20.58 \\
\hline $35-39$ years & 30.57 & 36.04 & 32.30 \\
\hline 40-44 years & 18.16 & 29.36 & 29.79 \\
\hline $45-50$ years & 2.82 & 2.87 & 5.07 \\
\hline \multicolumn{4}{|l|}{ Rural areas (\%) } \\
\hline 20-24 years & 1.90 & 1.94 & 2.00 \\
\hline $25-29$ years & 6.08 & 6.41 & 6.53 \\
\hline 30-34 years & 11.17 & 13.49 & 14.26 \\
\hline $35-39$ years & 16.21 & 22.80 & 21.76 \\
\hline 40-44 years & 13.70 & 26.35 & 24.74 \\
\hline $45-50$ years & 3.29 & 4.11 & 5.46 \\
\hline
\end{tabular}

${ }^{a}$ Age-standardized to the 6 th population census in Zhejiang province, 2010

rounds of under-reporting investigations and based on the relevant data in 2007 and 2016 [21, 45], the underreporting proportion of diabetes (including GDM) was reported to be $45.07 \%$ and $22.05 \%$, which indicated that our reported rate was underestimated. Third, there are different GDM diagnostic criteria at present and may influence the GDM prevalence across the studies. In multivariable Poisson regression models, we adjusted for age, residence area and calendar year as possible as we can, while other GDM related factors including obesity status, physical activity level and dietary behaviors were not considered. Besides, the number of GDM cases in some specific years was relatively small, which would decrease the statistical power to explore the time trend of GDM in the analysis.
Table 5. Average annual percentage change of gestational diabetes mellitus prevalence by demographic factors

\begin{tabular}{|c|c|c|c|}
\hline \multirow[t]{2}{*}{ Characteristic } & \multirow{2}{*}{$\begin{array}{l}\text { Average annual } \\
\text { percentage change } \\
\text { (\%) }\end{array}$} & \multicolumn{2}{|l|}{$95 \% \mathrm{Cls}$} \\
\hline & & Lower (\%) & Upper (\%) \\
\hline \multicolumn{4}{|l|}{ Overall } \\
\hline $20-24$ years & -4.38 & -7.27 & -1.40 \\
\hline $25-29$ years & -1.35 & -2.66 & 0.00 \\
\hline 30-34 years & 5.23 & 3.83 & 6.66 \\
\hline $35-39$ years & 8.51 & 6.70 & 10.34 \\
\hline 40-44 years & 28.08 & 23.92 & 32.37 \\
\hline $45-50$ years & 32.35 & 15.08 & 52.22 \\
\hline 20-50 years & 5.48 & 4.67 & 6.30 \\
\hline \multicolumn{4}{|l|}{ Urban areas } \\
\hline 20-24 years & -12.82 & -16.82 & -8.63 \\
\hline $25-29$ years & -6.01 & -7.76 & -4.22 \\
\hline 30-34 years & -1.20 & -3.02 & 0.65 \\
\hline $35-39$ years & 2.51 & 0.10 & 4.97 \\
\hline 40-44 years & 25.78 & 19.79 & 32.06 \\
\hline $45-50$ years & 37.49 & 10.06 & 71.74 \\
\hline $20-50$ years & 0.00 & -1.08 & 1.10 \\
\hline \multicolumn{4}{|l|}{ Rural areas } \\
\hline 20-24 years & 2.53 & -1.56 & 6.79 \\
\hline $25-29$ years & 3.60 & 1.66 & 5.58 \\
\hline 30-34 years & 12.70 & 10.53 & 14.91 \\
\hline $35-39$ years & 14.79 & 12.11 & 17.54 \\
\hline 40-44 years & 30.04 & 24.34 & 36.00 \\
\hline $45-50$ years & 29.07 & 7.81 & 54.52 \\
\hline 20-50 years & 11.28 & 10.07 & 12.51 \\
\hline
\end{tabular}

Multivariable Poisson regression models with the calendar year as a continuous variable and adjusting for the other covariates

$\mathrm{Cl}$ confidence interval

\section{Conclusions}

In conclusion, this study suggested a significant increase in the prevalence of GDM among Chinese female population in Zhejiang province during 20162018 , especially in women characterized by advanced age and rural areas.

\section{Abbreviations}

GDM: Gestational diabetes mellitus; IDF: International Diabetes Federation; CDC: Disease control and prevention; PRR: Prevalence rate ratio; $\mathrm{Cl}$ : Confidence interval; BMI: Body mass index; CKB: China Kadoorie Biobank.

\section{Acknowledgements}

We thank all of the cases and staff in local CDCs for their participation.

\section{Authors' contributions}

MW designed the study and wrote the manuscript. MW collected, analyzed the data with WWG, JP, FRF, HW and XYZ. Professor RYH, ZJM and MY gave much advice and directions in both study design and preparing of the manuscript. All the authors have read and approved the final submitted version. 


\section{Funding}

This work was supported by grant from Zhejiang Medical and Health Technology Project (2021 KY614). The funding body plays no role in the design of the study and collection, analysis, and interpretation of data and in writing the manuscript.

\section{Availability of data and materials}

The datasets generated and/or analyzed during the current study are not publicly available due individual privacy information protection but are available from the corresponding author on reasonable request.

\section{Ethics approval and consent to participate}

This study was carried out in accordance with the "Declaration of Helsinki" and the informed consents were obtained from cases and approved by the Ethics Committee of Zhejiang CDC.

\section{Consent for publication}

Not applicable.

\section{Competing interests}

The authors declare that they have no competing interests.

Received: 21 August 2020 Accepted: 30 December 2020

Published online: 19 January 2021

\section{References}

1. International Diabetes Federation. IDF Diabetes atlas-9th edition 2019 Available at https://diabetesatlas.org/en/sections/worldwide-toll-ofdiabetes.html (Accessed March, 2020)

2. Chiefari E, Arcidiacono B, Foti D, Brunetti A. Gestational diabetes mellitus: an updated overview. J Endocrinol Invest. 2017;40:899-909. https://doi. org/10.1007/s40618-016-0607-5.

3. Kc K, Shakya S, Zhang H. Gestational diabetes mellitus and macrosomia: a literature review. Ann NutrMetab. 2015;66(Suppl 2):14-20. https://doi. org/10.1159/000371628.

4. Kramer CK, Campbell S, Retnakaran R. Gestational diabetes and the risk of cardiovascular disease in women: a systematic review and metaanalysis. Diabetologia. 2019;62:905-14. https://doi.org/10.1007/s0012 5-019-4840-2

5. Reece EA, Leguizamón G, Wiznitzer A. Gestational diabetes: the need for a common ground. Lancet. 2009;373:1789-97. https://doi.org/10.1016/ S0140-6736(09)60515-8.

6. Perng W, Ringham BM, Smith HA, Michelotti G, Kechris KM, Dabelea D. A prospective study of associations between in utero exposure to gestational diabetes mellitus and metabolomic profiles during late childhood and adolescence. Diabetologia. 2020;63:296-312. https://doi. org/10.1007/s00125-019-05036-z.

7. Perng W, Hockett CW, Sauder KA, Dabelea D. In utero exposure to gestational diabetes mellitus and cardiovascular risk factors in youth: a longitudinal analysis in the EPOCH cohort. PediatrObes. 2020. https://doi. org/10.1111/ijpo.12611

8. Wang J, Wang L, Liu H, Zhang S, Leng J, Li W, et al. Maternal gestational diabetes and different indicators of childhood obesity: a large study. Endocr Connect. 2018;7:1464-71. https://doi.org/10.1530/EC-18-0449.

9. Jiwani A, Marseille E, Lohse N, Damm P, Hod M, Kahn JG. Gestational diabetes mellitus: results from a survey of country prevalence and practices. J MaternFetal Neonatal Med. 2012;25:600-10. https://doi. org/10.3109/14767058.2011.587921.

10. Xu T, Dainelli L, Yu K, Ma L, Silva Zolezzi I, Detzel P, et al. The short-term health and economic burden of gestational diabetes mellitus in China: a modelling study. BMJ Open. 2017;7:e018893. https://doi.org/10.1136/ bmjopen-2017-018893.

11. Natamba BK, Namara AA, Nyirenda MJ. Burden, risk factors and maternal and offspring outcomes of gestational diabetes mellitus (GDM) in sub-Saharan Africa (SSA): a systematic review and meta-analysis. BMC Pregnancy Childbirth. 2019;19:450. https://doi.org/10.1186/s1288 4-019-2593-z.
12. Lee KW, Ching SM, Ramachandran V, Yee A, Hoo FK, Chia YC, et al. Prevalence and risk factors of gestational diabetes mellitus in Asia: a systematic review and meta-analysis. BMC Pregnancy Childbirth. 2018;18:494. https://doi.org/10.1186/s12884-018-2131-4.

13. Wong VW. Gestational diabetes mellitus in five ethnic groups: a comparison of their clinical characteristics. Diabet Med. 2012;29:366-71. https://doi.org/10.1111/j.1464-5491.2011.03439.x.

14. Koo BK, Lee JH, Kim J, Jang EJ, Lee CH. Prevalence of gestational diabetes mellitus in Korea: a national health insurance database study. PLoS ONE. 2016;11:e0153107. https://doi.org/10.1371/journal.pone.0153107.

15. Yang H, Wei Y, Gao X, Xu X, Fan L, He J, et al. Risk factors for gestational diabetes mellitus in Chinese women: a prospective study of 16,286 pregnant women in China. Diabet Med. 2009;26:1099-104. https://doi. org/10.1111/j.1464-5491.2009.02845.X.

16. Xu X, Liu Y, Liu D, Li X, Rao Y, Sharma M, et al. Prevalence and determinants of gestational diabetes mellitus: a cross-sectional study in China. Int J Environ Res Public Health. 2017;14:E1532. https://doi.org/10.3390/ ijerph14121532.

17. Yang X, Hsu-Hage B, Zhang H, Yu L, Dong L, Li J, et al. Gestational diabetes mellitus in women of single gravidity in Tianjin City, China. Diabet Care. 2002;25:847-51. https://doi.org/10.2337/diacare.25.5.847.

18. Zhang F, Dong L, Zhang CP, Li B, Wen J, Gao W, et al. Increasing prevalence of gestational diabetes mellitus in Chinese women from 1999 to 2008. Diabet Med. 2011;28:652-7. https://doi.org/10.111 1/j.1464-5491.2010.03205.x.

19. Leng J, Shao P, Zhang C, Tian H, Zhang F, Zhang S, et al. Prevalence of gestational diabetes mellitus and its risk factors in Chinese pregnant women: a prospective population-based study in Tianjin, China. PLoS ONE. 2015;10:e0121029. https://doi.org/10.1371/journal.pone.0121029.

20. Yan B, Yu Y, Lin M, Li Z, Wang L, Huang P, et al. High, but stable, trend in the prevalence of gestational diabetes mellitus: a population-based study in Xiamen. China J Diabetes Investig. 2019;10:1358-64. https:// doi.org/10.1111/jdi.13039.

21. Wang M, Gong WW, Pan J, Fei FR, Wang H, Yu M, et al. Incidence and time trends of type 2 diabetes mellitus among adults in Zhejiang Province, China, 2007-2017. J Diabet Res. 2020;2020:2597953. https:// doi.org/10.1155/2020/2597953.

22. Wang M, Hu RY, Wu HB, Pan J, Gong WW, Guo LH, et al. Cancer risk among patients with type 2 diabetes mellitus: a population-based prospective study in China. Sci Rep. 2015;5:11503. https://doi.org/10.1038/ srep 11503.

23. Chinese Medical Association. The Diagnostic Criteria for GDM (2014). Chin J ObstetGynecol. 2014;8:561-9. https://doi.org/10.3760/ cma.j.issn.0529-567x.2014.08.001.(InChinese).

24. Kragelund Nielsen K, Andersen GS, Damm P, Andersen AN. Gestational diabetes risk in migrants. A nationwide, register-based study of all births in Denmark 2004 to 2015. J Clin Endocrinol Metab. 2020; 105: pii: dgaa024. https://doi.org/10.1210/clinem/dgaa024.

25. Ovesen PG, Fuglsang J, Andersen MB, Wolff C, Petersen OB, David $\mathrm{MH}$. Temporal trends in gestational diabetes prevalence, treatment, and outcomes at Aarhus University Hospital, Skejby, between 2004 and 2016. J Diabetes Res. 2018;2018:5937059. https://doi. org/10.1155/2018/5937059.

26. Domanski G, Lange AE, Ittermann T, Allenberg H, Spoo RA, Zygmunt $M$, et al. Evaluation of neonatal and maternal morbidity in mothers with gestational diabetes: a population-based study. BMC Pregnancy Childbirth. 2018;18:367. https://doi.org/10.1186/s12884-018-2005-9.

27. Jovanovič L, Liang Y, Weng W, Hamilton M, Chen L, Wintfeld N. Trends in the incidence of diabetes, its clinical sequelae, and associated costs in pregnancy. DiabetMetab Res Rev. 2015;31:707-16. https://doi. org/10.1002/dmrr.2656.

28. Casagrande SS, Linder B, Cowie CC. Prevalence of gestational diabetes and subsequent Type 2 diabetes among US women. Diabetes Res ClinPract. 2018;141:200-8. https://doi.org/10.1016/j.diabres.2018.05.010.

29. Ignell C, Claesson R, Anderberg E, Berntorp K. Trends in the prevalence of gestational diabetes mellitus in southern Sweden, 2003-2012. ActaObstetGynecolScand. 2014;93:420-4. https://doi.org/10.1111/ aogs. 12340.

30. Khajehei M, Assareh $\mathrm{H}$. Temporal trend of diabetes in pregnant women and its association with birth outcomes, 2011 to 2017. J DiabetComplic. 2020;34:107550. https://doi.org/10.1016/j.jdiacomp.2020.107550. 
31. Yang W, Lu J, Weng J, Jia W, Ji L, Xiao J, et al. Prevalence of diabetes among men and women in China. N Engl J Med. 2010;362:1090-101. https://doi.org/10.1056/NEJMoa0908292.

32. Wang L, Gao P, Zhang M, Huang Z, Zhang D, Deng Q, et al. Prevalence and ethnic pattern of diabetes and prediabetes in China in 2013. JAMA 2017;317:2515-23. https://doi.org/10.1001/jama.2017.7596.

33. Giannakou K, Evangelou E, Yiallouros P, Christophi CA, Middleton N, Papatheodorou E, et al. Risk factors for gestational diabetes: an umbrella review of meta-analyses of observational studies. PLOS ONE. 2019;14:e0215372. https://doi.org/10.1371/journal.pone.0215372.

34. Ferrara A. Increasing prevalence of gestational diabetes mellitus: a public health perspective. Diabetes Care. 2007;30(Suppl 2):S141-6. https://doi. org/10.2337/dc07-s206.

35. Tian Y, Jiang C, Wang M, Cai R, Zhang Y, He Z, et al. BMI, leisure-time physical activity, and physical fitness in adults in China: results from a series of national surveys, 2000-14. Lancet Diabetes Endocrinol. 2016;4:487-97. https://doi.org/10.1016/S2213-8587(16)00081-4.

36. Aune D, Sen A, Henriksen T, Saugstad OD, Tonstad S. Physical activity and the risk of gestational diabetes mellitus: a systematic review and dose-response meta-analysis of epidemiological studies. Eur J Epidemiol. 2016;31:967-97. https://doi.org/10.1007/s10654-016-0176-0.

37 Mijatovic-Vukas J, Capling L, Cheng S, Stamatakis E, Louie J, Cheung NW, et al. Associations of diet and physical activity with risk for gestational diabetes mellitus: a systematic review and meta-analysis. Nutrients. 2018;10:E698. https://doi.org/10.3390/nu10060698.

38. Lewington S, Li L, Murugasen S, Hong LS, Yang L, Guo Y, et al. Temporal trends of main reproductive characteristics in ten urban and rural regions of China: the China Kadooriebiobank study of 300,000 women. Int J Epidemiol. 2014;43:1252-62. https://doi.org/10.1093/ije/dyu035.

39. Li Y, Ren X, He L, Li J, Zhang S, Chen W. Maternal age and the risk of gestational diabetes mellitus: a systematic review and meta-analysis of over
120 million participants. Diabetes Res ClinPract. 2020;162:108044. https:// doi.org/10.1016/j.diabres.2020.108044.

40. Dos Santos PA, Madi JM, da Silva ER, Vergani DOP, de Araújo BF, Garcia RMR. Gestational diabetes in the population served by Brazilian Public Health Care. Prevalence and risk factors. Rev Bras GinecolObstet. 2020;42:12-8. https://doi.org/10.1055/s-0039-1700797.

41. Liu J, Liu M, Zhang S, Ma Q, Wang Q. Intent to have a second child among Chinese women of childbearing age following China's new universal two-child policy: a cross-sectional study. BMJ Sex Reprod Health. 2019; pii: bmjsrh-2018-200197. https://doi.org/10.1136/bmjsrh-2018-200197.

42. Bardenheier BH, Imperatore G, Gilboa SM, Geiss LS, Saydah SH, Devlin $\mathrm{HM}$, et al. Trends in gestational diabetes among hospital deliveries in 19 US States, 2000-2010. Am J Prev Med. 2015; 49: 12-9. https://doi. org/10.1016/j.amepre.2015.01.026.

43. Zargar AH, Sheikh MI, Bashir MI, Masoodi SR, Laway BA, Wani Al, et al. Prevalence of gestational diabetes mellitus in Kashmiri women from the Indian subcontinent. Diabet Res ClinPract. 2004;66:139-45. https://doi. org/10.1016/j.diabres.2004.02.023.

44. Aydın H, Çelik Ö, Yazıcı D, Altunok Ç, Tarçın Ö, Deyneli O, et al. Prevalence and predictors of gestational diabetes mellitus: a nationwide multicentre prospective study. Diabet Med. 2019;36:221-7. https://doi.org/10.1111/ dme.13857.

45. Xiao YY, Hu RY, Gong WW, Wang H, Zhang XW, Yu M. Analysis of underreporting of birth, death, infectious diseases and chronic diseases in Zhejiang Province, 2007. Dis Surveil. 2008;23:727-30. https://doi. org/10.3784/j.issn.1003-9961.2008.11.021 ((in Chinese)).

\section{Publisher's Note}

Springer Nature remains neutral with regard to jurisdictional claims in published maps and institutional affiliations.
Ready to submit your research? Choose BMC and benefit from:

- fast, convenient online submission

- thorough peer review by experienced researchers in your field

- rapid publication on acceptance

- support for research data, including large and complex data types

- gold Open Access which fosters wider collaboration and increased citations

- maximum visibility for your research: over $100 \mathrm{M}$ website views per year

At BMC, research is always in progress.

Learn more biomedcentral.com/submissions 